\title{
Management of osteoporosis in the aging male: Focus on zoledronic acid
}

This article was published in the following Dove Press journal:

Clinical Interventions in Aging

15 June 2009

Number of times this article has been viewed

\author{
Paul K Piper Jr' \\ Ugis Gruntmanis ${ }^{1,2}$ \\ 'Division of Endocrinology \\ and Metabolism, University of Texas \\ Southwestern Medical Center, Dallas, \\ TX USA; ${ }^{2}$ North Texas Veterans Affairs \\ Medical Center, Dallas, TX USA
}

\begin{abstract}
Osteoporosis in the aging male remains an important yet under-recognized and undertreated disease. Current US estimates indicate that over 14 million men have osteoporosis or low bone mass, and men suffer approximately 500,000 osteoporotic fractures each year. Men experience fewer osteoporotic fractures than women but have higher mortality after fracture. Bisphosphonates are potent antiresorptive agents that inhibit osteoclast activity, suppress in vivo markers of bone turnover, increase bone mineral density, decrease fractures, and improve survival in men with osteoporosis. Intravenous zoledronic acid may be a preferable alternative to oral bisphosphonate therapy in patients with cognitive dysfunction, the inability to sit upright, or significant gastrointestinal pathology. Zoledronic acid (Reclast) is approved in the US as an annual $5 \mathrm{mg}$ intravenous infusion to treat osteoporosis in men. The zoledronic acid (Zometa) $4 \mathrm{mg}$ intravenous dose has been studied in the prevention of bone loss associated with androgen deprivation therapy.
\end{abstract}

Keywords: male osteoporosis, bisphosphonates, zoledronic acid

\section{Osteoporosis in the aging male}

Osteoporosis is a systemic skeletal disorder characterized by low bone mass and microarchitectural deterioration of bone tissue, with a consequent increase in bone fragility and susceptibility to fracture. ${ }^{1}$ The National Osteoporosis Foundation (NOF) estimates that over 14 million American men had osteoporosis or low bone mass in 2002. ${ }^{2}$ One in four men older than 60 years of age will experience a fracture, ${ }^{3}$ yet age-related bone loss in men remains under-recognized and undertreated.

Sixteen percent of men older than 50 and $35 \%$ men older than 85 fall each year. ${ }^{4}$ Hip fractures in men increase mortality by fourfold in the first three months after fracture, ${ }^{5}$ and one-year mortality reaches $20 \% .{ }^{6}$ Epidemiologic surveys consistently show higher mortality in men than women of similar ages after fracture. ${ }^{7}$ Among survivors of hip fracture, more than 1 in 4 becomes disabled in the following year, ${ }^{8}$ and nearly 1 in 5 will require long-term nursing home care. ${ }^{9}$ Care for patients after hip fracture is expensive to society. In the US, direct costs for patients with osteoporotic fractures is estimated at up to $\$ 18$ billion/year in 2002 dollars. White men account for $18 \%$ of these costs, or $\$ 3.2$ billion annually..$^{10}$ Vertebral fractures also increase long-term mortality, ${ }^{3,7,11}$ cause persistent back pain, deformity, functional decline, and diminished quality of life.

Importantly, the prevalence of osteoporosis and osteoporotic fractures are expected to rise as men live longer. The NOF predicts that there will be 20.5 million American
Correspondence: Ugis Gruntmanis 5323 Harry Hines Blvd,Y5 332, Dallas, TX 75390-8857, USA

Tel +l 2146483465

Email ugis.gruntmanis@utsouthwestern.edu 
men with osteoporosis or low bone mass by $2020 .^{2}$ By 2025 , annual costs for osteoporosis-related fractures is expected to be $\$ 25.3$ billion. $^{2}$

\section{Identifying men at high risk for osteoporotic fracture}

Previous fracture is the strongest predictor of any future fracture. The Osteoporotic Fractures in Men (MrOS) Study ${ }^{12}$ followed 5995 men aged 65 and older and showed that men with a history of fracture after 50 years had a twofold increased risk of nonvertebral fracture compared to men without prior fracture. A second important predictor of fracture is advancing age. The Dubbo Study showed that, compared to men aged 70-74 years, men older than 80 years had 28 times as many vertebral fractures, nine times as many hip fractures, and nearly five times as many overall fractures. ${ }^{13}$ Third, bone mineral density (BMD) predicts fracture risk. The use of BMD by dual energy X-ray absorptiometry (DEXA) to predict fracture risk is comparable to the use of blood pressure to predict stroke and is substantially better than using serum cholesterol to predict the risk of myocardial infarction. The MrOS investigators ${ }^{12}$ also found that tricyclic antidepressant use (hazard ratio [HR] 2.36), the inability to complete a narrow walk trial (HR 1.70), falls in previous year (HR 1.59), and depressed mood (HR 1.72) all increased fracture risk independent of BMD.

Bone quality indicators such as cortical thickness, microarchitecture, turnover, porosity, damage accumulation, and the rate and quality of mineralization are other important predictors of fracture, yet they are difficult to incorporate into clinical practice. ${ }^{14}$ Compared to women, men have bones with larger cross-sectional areas, and as men age they tend to preserve trabecular number. Apart from bone density, both of these factors are thought to ameliorate fracture risk.

In addition to age-related bone loss, osteoporosis in men is frequently secondary to other comorbidities such as glucocorticoid use, hypogonadism, vitamin D deficiency, cigarette smoking, heavy alcohol intake, immobility, or inadequate dietary calcium intake. Studies among ambulatory men with osteoporosis indicate that $30 \%-64 \%$ have at least one identifiable risk factor. ${ }^{15,16}$ The World Health Organization (WHO) has developed the FRAX ${ }^{\mathrm{TM}}$ fracture risk assessment tool, a group of country- and ethnicity-specific risk calculators which allow an estimate of fracture risk based on historical and exam findings. ${ }^{17}$

\section{Treatment strategies}

Traditional nonpharmacologic therapies include treatments intended to increase bone mineral density, prevent falls, and prevent fractures with falls. Several recent papers have reviewed the literature on fall prevention, hip protectors, and calcium and vitamin D supplementation in men. ${ }^{14,18,19}$ Weight bearing exercise can prevent falls ${ }^{20}$ and increase BMD. ${ }^{21}$ Inadequate dietary calcium and vitamin D intake are risk factors for osteoporosis. The NOF recommends that individuals 50 years old and older consume $1200 \mathrm{mg}$ calcium and 800-1000 IU vitamin D daily. Several studies of calcium and vitamin D supplementation have shown increased BMD, decreased fracture risk, ${ }^{22-24}$ and even decreased mortality $^{23}$ irrespective of baseline 25-hydroxyvitamin D levels. However, another large randomized controlled trial of calcium and vitamin $\mathrm{D}$ in secondary prevention of osteoporotic fractures showed no benefit. ${ }^{25}$

The NOF recommends drug treatment for men aged 50 and older with prior hip or vertebral fracture, with osteoporosis (T-score $\leq-2.5$ at the femoral neck or spine), or with osteopenia (T-score between -1.0 and -2.5 at the femoral neck or spine) and an absolute 10 -year risk of hip fracture $\geq 3 \%$ or 10 -year risk of a major osteoporosis-related fracture $\geq 20 \%$ based on the FRAX calculation. ${ }^{26}$ Drugs for the treatment of osteoporosis can be classified into antiresorptive or anabolic agents. Antiresorptive agents, or drugs that inhibit osteoclast action, include most of the commonly used therapies in men such as calcitonin, testosterone, and bisphosphonates.

\section{Calcitonin}

Trovas and colleagues ${ }^{27}$ randomized 28 osteoporotic men to receive daily intranasal calcitonin 200 IU or placebo. At 12 months, the treated group had significantly suppressed markers of bone turnover and greater BMD at the lumbar spine but not hip. Toth and colleagues ${ }^{28}$ studied 71 men with idiopathic osteoporosis but no prior fracture. In these men, intranasal calcitonin daily during alternate months for 18 months significantly increased BMD at the spine and hip and decreased vertebral fractures.

Calcitonin is not approved in the US for the treatment of male osteoporosis.

\section{Testosterone}

Studies have consistently shown that testosterone replacement improves BMD in hypogonadal men. ${ }^{29-32}$ Snyder and colleagues ${ }^{31}$ randomized 108 men aged over 65 years without osteoporosis to daily testosterone patch or placebo. They found no treatment effect on BMD in the group as a whole or in men with baseline testosterone level $>400 \mathrm{ng} / \mathrm{dL}$. Anderson and colleagues ${ }^{33}$ studied intramuscular testosterone injections every two weeks in men 
with osteoporosis and prior vertebral fracture. In this population, the authors found that testosterone therapy suppressed markers of bone turnover and significantly increased lumbar spine BMD.

No studies have assessed the effect of testosterone replacement on fracture risk, and testosterone is not approved in the US for the treatment of osteoporosis.

\section{Teriparatide}

Teriparatide (1-34 PTH), stimulates bone formation. Teriparatide has been shown to raise BMD in men at the hip and spine more than alendronate alone, ${ }^{34,35}$ and it reduces vertebral fractures by $90 \%{ }^{35}$

Teriparatide is approved by the US FDA for treatment of osteoporosis in men considered at high risk for fracture.

\section{Bisphosphonates}

Bisphosphonates are synthetic pyrophosphate analogues with a P-C-P backbone that is resistant to hydrolysis and two phosphate groups that bind hydroxyapatite with high affinity. The central carbon binds the $\mathrm{R} 1$ side chain, often a hydroxyl group, which binds calcium and allows for more stable interaction with the bone matrix. ${ }^{36}$ The longer R2 side chain gives each bisphosphonate its characteristic properties and potency. Bisphosphonates can be classified based on the presence or absence of a nitrogen atom in the $\mathrm{R} 2$ side chain. The nitrogen-containing bisphosphonates (alendronate, risedronate, ibandronate, and zoledronic acid) are more potent inhibitors of osteoclast action. ${ }^{37}$

\section{Mechanism of action}

Bisphosphonates are poorly absorbed through the gut, with less than $1 \%$ bioavailability after oral administration. ${ }^{38}$ The kidneys excrete approximately $50 \%$ of the drug unchanged. ${ }^{39}$ The remaining bisphosphonates bind hydroxyapatite crystals on the bone surface with high affinity, where they are internalized by and accumulate in osteoclasts.

Within the osteoclast, the nonnitrogen containing bisphosphonates (etidronate, tiludronate) are incorporated into adenosine triphosphate (ATP). These nascent nonhydrolyzable ATP analogs are toxic to osteoclasts, leading to mitochondrial inhibition and osteoclast apoptosis. ${ }^{40}$ The nitrogen-containing bisphosphonates inhibit the enzyme farnesyl pyrophosphate synthase (FPPS) in the HMGCoA reductase pathway leading to cholesterol synthesis. In addition to cholesterol synthesis, this pathway produces the intermediate metabolites farnesol and gerinylgeranol that are necessary for protein prenylation. Prenylation is the posttranslational attachment of hydrophobic prenyl groups to cytoplasmic proteins to allow binding to the cell membrane. ${ }^{40}$ Such modification allows the Ras superfamily of GTPases to exert changes in cytoskeletal function that produce the characteristic osteoclast ruffled border and allow osteoclast attachment to bone. ${ }^{41}$ Biopsies of alendronate-treated bone show greater numbers of osteoclasts and abnormal giant, hypernucleated osteoclasts detached from bone. The number of osteoclasts increased with cumulative dose of alendronate, suggesting that the drug may prolong osteoclast survival. ${ }^{42}$ Bisphosphonate potency, the ability to inhibit bone resorption in vivo, is directly related to drug ability to inhibit FPPS in vitro. ${ }^{37}$ Nitrogencontaining bisphosphonates also inhibit osteoclast precursor differentiation and inhibit osteoblast-mediated osteoclast activation. ${ }^{38}$

\section{Evidence of benefit}

\section{Pamidronate}

Several randomized controlled trials of pamidronate for the treatment of osteoporosis include men. Ryan and colleagues ${ }^{43}$ randomized 122 subjects with prior vertebral fracture to oral pamidronate $300 \mathrm{mg} /$ day (group A) for four weeks every 16 weeks, $150 \mathrm{mg} /$ day (group B) for four weeks every eight weeks or placebo (group C). At 2 years, the authors reported significant reductions in serum osteocalcin (29\% group A and $33 \%$ group $\mathrm{B}$ ) and urinary deoxypyridinoline (16\% group A, $21 \%$ group $\mathrm{B}, \mathrm{p}<0.01$ for all comparisons to placebo). They found significant increases in BMD at the spine, hip, and total body (See Table 2).

Brumsen and colleagues ${ }^{44}$ randomized 101 subjects with prior vertebral fracture to oral pamidronate $150 \mathrm{mg}$ /day or placebo. At three years, the investigators found significant reductions in urinary hydroxyproline and serum alkaline phosphatase and significant increases in BMD at the lumbar spine (See Table 2). Men and women had similar increase in BMD in response to pamidronate. There were significantly fewer morphometric vertebral fractures (ARR 22\%) in the pamidronate group, and the number needed to treat (NNT)

Table I Relative potency of bisphosphonates ${ }^{37}$

\begin{tabular}{ll}
\hline Drug & Relative potency \\
\hline Pamidronate (Aredia) & $\mathrm{I}$ \\
Alendronate (Fosamax) & 4 \\
lbandronate (Boniva) & 10 \\
Risedronate (Actonel) & 20 \\
Zoledronic acid (Zometa, Reclast) & 67 \\
\hline
\end{tabular}


Table 2 Studies of bisphosphonates for the treatment of osteoporosis in men

\begin{tabular}{|c|c|c|c|c|c|c|c|c|c|c|c|c|}
\hline \multirow[t]{2}{*}{ Citation } & \multirow[t]{2}{*}{ Drug } & \multirow{2}{*}{$\begin{array}{l}\text { Study } \\
\text { design }\end{array}$} & \multirow[t]{2}{*}{$\mathbf{N}$} & \multirow{2}{*}{$\begin{array}{l}\text { Follow-up } \\
\text { (mo) }\end{array}$} & \multirow[t]{2}{*}{ Men } & \multirow[t]{2}{*}{ Avg age } & \multicolumn{3}{|c|}{ Fracture RRR } & \multicolumn{3}{|c|}{$\Delta \%$ increase BMD } \\
\hline & & & & & & & Any & Vert & NV & $\mathbf{H}$ & $\mathbf{F N}$ & LS \\
\hline Ryan et al ${ }^{43}$ & pamidronate & RCT & 122 & 24 & $9 \%$ & 65.2 & & & & & & $3.5 \%-5.0 \%$ \\
\hline Brumsen et $\mathrm{al}^{44}$ & pamidronate & $\mathrm{RCT}$ & 101 & 36 & $23 \%$ & 64.5 & & $67 \%$ & $67 \%$ & & NS & $5.3 \%$ \\
\hline Boutsen et $\mathrm{al}^{45}$ & pamidronate & $\mathrm{RCT}$ & 27 & 12 & $44 \%$ & 57 & & & & $3.2 \%-4.8 \%$ & $4.3 \%$ & $6.3 \%-6.9 \%$ \\
\hline Ho et $\mathrm{al}^{46}$ & alendronate & PU & 123 & 12 & $57 \%$ & 64.2 & & & & & NS & $6.4 \%-7.0 \%$ \\
\hline Orwoll et a $\left.\right|^{47}$ & alendronate & $\mathrm{RCT}$ & 241 & 24 & $100 \%$ & 63 & & $86 \%$ & NS & $2.6 \%$ & $2.6 \%$ & $5.3 \%$ \\
\hline Ringe et $\mathrm{a}^{48}$ & alendronate & RCT & 134 & 36 & $100 \%$ & 53 & & $57 \%$ & NS & & $3.5 \%$ & $8.0 \%$ \\
\hline Ringe et a $\left.\right|^{50}$ & risedronate & $\mathrm{RCT}$ & 316 & 12 & $100 \%$ & 56.9 & & $60 \%$ & NS & $2.3 \%$ & $1.6 \%$ & $3.7 \%$ \\
\hline Boonen et $\mathrm{al}^{51}$ & risedronate & $\mathrm{RCT}$ & 284 & 24 & $100 \%$ & 60.7 & NS & & & & & $4.6 \%$ \\
\hline Reid et $\mathrm{al}^{52}$ & risedronate & RCT & 184 & 12 & $100 \%$ & 57.7 & & $82 \%$ & & & & \\
\hline Sato et $\mathrm{al}^{53}$ & risedronate & $\mathrm{RCT}$ & 280 & 18 & $100 \%$ & 76.3 & & & $75 \%$ & & & \\
\hline Kanaji et a ${ }^{56}$ & risedronate & $\mathrm{RCT}$ & 23 & 12 & $100 \%$ & $63-87$ & & $56 \%$ & & & & \\
\hline Lamy et al ${ }^{55}$ & ibandronate & PU & 14 & 24 & $100 \%$ & 57 & & & & $0.9 \%$ & $1.4 \%$ & $6.7 \%$ \\
\hline Ringe et $\mathrm{a}^{66}$ & ibandronate & $\mathrm{RCT}$ & 115 & 36 & $46 \%$ & 64 & & $62 \%$ & NS & & $3.3 \%$ & $10.7 \%$ \\
\hline HORIZON-RFT 69 & zoledronic acid & $\mathrm{RCT}$ & 2127 & 36 & $24 \%$ & 74.5 & $35 \%$ & $46 \%$ & $27 \%$ & $6.4 \%$ & $4.3 \%$ & \\
\hline Poole et $\mathrm{a}^{72}$ & zoledronic acid & $\mathrm{RCT}$ & 27 & 12 & $78 \%$ & 69.8 & & & & $5.5 \%$ & NS & \\
\hline Bolland et $\mathrm{a}^{75}$ & zoledronic acid & $\mathrm{RCT}$ & 43 & 24 & $100 \%$ & 49.1 & & & & $4.6 \%$ & & $6.3 \%$ \\
\hline Brown et $\mathrm{al}^{79}$ & zoledronic acid & PU & 66 & 36 & $100 \%$ & 42 & & & & $4.3 \%$ & & $4.8 \%$ \\
\hline
\end{tabular}

Abbreviations: $\mathrm{RCT}$, prospective, randomized controlled trial; $\mathrm{PU}$, prospective, unrandomized trial; vert, vertebral; $\mathrm{NV}$, nonvertebral; NS, not significant; $\mathrm{H}$, total hip; FN, femoral neck; LS, lumbar spine. All comparisons are statistically significant with $p<0.05$.

with pamidronate for three years to prevent one vertebral fracture was 5. Six subjects in the placebo group and three pamidronate-treated subjects experienced symptomatic vertebral fractures. Three subjects in the placebo group and one pamidronate-treated subject experienced nonvertebral fractures (ARR 4\%). At the end of three years, 53 of the study subjects agreed to participate in an open-label two year extension of the trial. There were equal numbers from the pamidronate and placebo groups, and all subjects received oral pamidronate $150 \mathrm{mg} /$ day. With pamidronate treatment, the differences in urinary hydroxyproline and serum alkaline phosphatase between the initial study groups disappeared. The BMD of the prior placebo group increased to greater extent compared to the prior treatment group such that, at the end of an additional two years there was no significant difference in femoral neck BMD between the groups. The subjects who received pamidronate for five years continued to have a small yet significant greater increase in lumbar spine BMD compared to those subjects who had initially received placebo.

Boutsen and colleagues ${ }^{45}$ studied 27 subjects who required initiation of long-term glucocorticoid therapy at a dose of at least $10 \mathrm{mg} /$ day prednisolone for polymyalgia rheumatica (16), inflammatory bowel disease (4), temporal arteritis (3), and rheumatoid arthritis (2). The subjects were randomized to receive a single dose IV pamidronate $90 \mathrm{mg}$ at the start of glucocorticoid therapy (group A); IV pamidronate $90 \mathrm{mg}$ once followed by $30 \mathrm{mg}$ IV pamidronate every three months (group B); and control (group C). Both treatment groups experienced significant decreases in bone-specific alkaline phosphatase, osteocalcin, and C-telopeptide at three months. At 12 months, however, all bone markers of the once-treated group had risen again and only group B observed a sustained decrease in bone resorption. At six and 12 months, there was significantly greater BMD at the lumbar spine, femoral neck, and total hip in both treatment groups compared to control (see Table 2). There were no fractures recorded during the 12 month study.

Pamidronate is not approved in the US for the treatment of osteoporosis in men or women.

\section{Alendronate}

Alendronate was the first bisphosphonate to be extensively studied in men. In a study by Ho and colleagues, ${ }^{46} 80$ subjects with either primary or secondary osteoporosis and prior vertebral fracture received alendronate $10 \mathrm{mg}$ daily. The investigators also followed 43 matched controls. Over 12 months follow-up, the investigators found significantly 


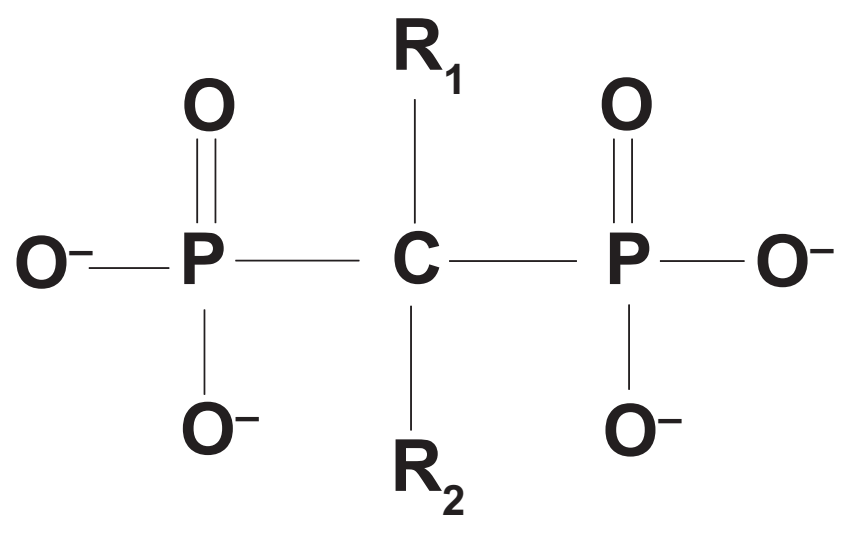

Figure I Generic bisphosphonate structure.

improved BMD at the lumbar spine and femoral trochanter but not femoral neck (See Table 2). Results were similar for women and men.

Orwoll and colleagues ${ }^{47}$ randomized 241 men with osteoporosis to $10 \mathrm{mg}$ daily alendronate or placebo. After two years of treatment, the authors observed a significant $59 \%$ decrease in urinary $\mathrm{N}$-telopeptide of type I collagen and $38 \%$ decrease in bone-specific alkaline phosphatase in the alendronate group. In the alendronate-treated group, bone mineral density at 24 months increased significantly at the lumbar spine, total hip and femoral neck compared to placebo. Quantitative analysis of spine radiographs revealed significantly fewer vertebral fractures in the alendronate group (aldosterone-renin ratio [ARR] 6.3\%) but no significant difference in nonvertebral fractures (See Table 2).

\begin{tabular}{|c|c|c|}
\hline Agent & $\mathrm{R}_{1}$ side chain & $\mathrm{R}_{2}$ side chain \\
\hline Etidronate & $-\mathrm{OH}$ & $-\mathrm{CH}_{3}$ \\
\hline Clodronate & $-\mathrm{Cl}$ & $-\mathrm{Cl}$ \\
\hline Tiludronate & $-H$ & $-\mathrm{S}-\langle\square-\mathrm{Cl}$ \\
\hline Pomidronate & $-\mathrm{OH}$ & $-\mathrm{CH}_{2}-\mathrm{CH}_{2}-\mathrm{NH}_{2}$ \\
\hline Neridronate & $-\mathrm{OH}$ & $-\left\{\mathrm{CH}_{2}\right\}_{5}-\mathrm{NH}_{2}$ \\
\hline Olpadronate & $-\mathrm{OH}$ & $\left.-\left\{\mathrm{CH}_{2}\right\}_{2} \mathrm{~N}_{2} \mathrm{CH}_{3}\right\}_{2}$ \\
\hline Alendronate & $-\mathrm{OH}$ & $-\left\{\mathrm{CH}_{2}\right\}_{3}-\mathrm{NH}_{2}$ \\
\hline Ibandronate & $-\mathrm{OH}$ & $-\mathrm{CH}_{2}-\mathrm{CH}_{2} \mathrm{~N}=\mathrm{CH}_{3}$ \\
\hline Risedronate & $-\mathrm{OH}$ & \\
\hline Zoledronate & $-\mathrm{OH}$ & \\
\hline
\end{tabular}

Figure 2 Comparison of structures of different bisphosphonates.
These findings were confirmed by Ringe and colleagues ${ }^{48}$ in an open label study of 134 men with osteoporosis randomized to $10 \mathrm{mg}$ daily alendronate or the vitamin $\mathrm{D}$ analog alfacalcidol $1 \mu \mathrm{g}$ daily. With three years follow-up, they observed significantly greater increases in BMD at the lumbar spine and femoral neck in the alendronate-treated group. The alendronate group had significantly fewer vertebral fractures (ARR $13.9 \%, p=0.04)$ and no difference in nonvertebral fractures (See Table 2).

A meta-analysis of the alendronate trials including 375 men $^{49}$ concluded that alendronate treatment significantly decreases the risk of vertebral fractures (odds ratio [OR] 0.36) in men with osteoporosis. There were not sufficient data to confirm a significant decrease in nonvertebral fractures.

Alendronate is approved in the US for the treatment of osteoporosis in men.

\section{Risedronate}

Ringe and colleagues ${ }^{50}$ studied risedronate in 316 men with primary or secondary osteoporosis. Over half of those enrolled had a vertebral fracture prior to the start of the study. Subjects were randomized to risedronate $5 \mathrm{mg}$ daily or control, and all received calcium and vitamin D supplementation. At 12 months, there was a significantly greater improvement in BMD at the lumbar spine, total hip, and femoral neck. At one year, the treated subjects experienced fewer vertebral fractures (ARR 7.6\%, $\mathrm{p}=0.028$ ), a nonsignificant $42 \%$ decrease in nonvertebral fractures, and significantly less back pain than the control group (See Table 2).

Boonen and colleagues ${ }^{51}$ randomized 284 men with osteoporosis but without prior fracture to weekly risedronate $35 \mathrm{mg}$ or placebo in 2:1 ratio. The risedronate-treated group had significant reductions in the bone turnover markers c-telopeptide, n-telopeptide, and bone-specific alkaline phosphatase at three months, and these effects persisted throughout the two-year study period. The treatment group also experienced significantly greater increases in BMD at the lumbar spine by three months and at the total hip and femoral neck by six months (see Table 2). These treatment differences increased throughout the study. The authors noted a nonsignificant trend toward overall fracture reduction, though the study was not powered to detect a difference.

Reid and colleagues ${ }^{52}$ studied 184 men enrolled in two RCT receiving daily risedronate $2.5 \mathrm{mg}$, risedronate $5 \mathrm{mg}$, or placebo for the prevention or treatment of glucocorticoid-induced osteoporosis (GIO). Prior to enrollment, the subjects had received either $<3$ months (prevention study) or $>6$ months (treatment study) chronic 
oral glucocorticoid therapy of at least $7.5 \mathrm{mg} /$ day prednisone or equivalent, most commonly for rheumatoid arthritis, lung disease, and polymyalgia rheumatica. At one year, the subjects treated with risedronate $5 \mathrm{mg}$ /day experienced $61 \%$ decrease in urinary n-telopeptide and $20 \%$ reduction in bone-specific alkaline phosphatase. The GIO treatment study group treated with risedronate $5 \mathrm{mg}$ experienced significant increases in BMD at the lumbar spine and femoral neck compared to baseline. In the GIO prevention study, risedronate $5 \mathrm{mg} /$ day prevented the significant loss in BMD at the hip and lumbar spine seen in the placebo group. The authors reported that risedronate $2.5 \mathrm{mg} /$ day produced similar yet smaller effects on BMD. When both risedronate treatment arms from both studies were combined, the authors found a $19 \%$ ARR in morphometric vertebral fractures at one year. However, fracture data were reported for only 96 of the 184 enrolled subjects.

Prior stroke is a risk factor for fracture, through immobility decreasing bone mineral density and by gait instability increasing risk for falls. Sato and colleagues ${ }^{53}$ studied 280 men 65 years or older after hemiplegic stroke. The subjects were randomized to risedronate $2.5 \mathrm{mg}$ daily or placebo and followed for 18 months. Urinary deoxypyridinoline concentration decreased significantly compared to baseline and compared to placebo within the first six months of risedronate treatment and remained stable thereafter. The authors assessed BMD at the second metacarpal bones on both hemiplegic and unaffected sides. On the hemiplegic side, metacarpal BMD increased $2.5 \%$ in the risedronate-treated and decreased $3.5 \%$ in the untreated group. On the unaffected side, metacarpal BMD increased $3.3 \%$ in the treated and decreased $2.0 \%$ in the unaffected side. Differences between groups were highly significant $(\mathrm{p}<0.001)$. During the study period, 87 men fell a total of 547 times. The risedronate group experienced fewer hip fractures (ARR 5.7\%) and overall fractures (ARR 8.6\%) though asymptomatic vertebral fractures were not assessed, and no vertebral fractures were reported (See Table 2). The NNT to prevent hip fracture was 16 .

Hypogonadism affects approximately 50\% men with leprosy due to gonadal atrophy from testicular Mycobacterium leprae infection. ${ }^{54}$ As a result, osteoporosis is very common in men with leprosy. Among 197 men with leprosy residing at a national leprosarium, Ishikawa and colleagues ${ }^{55}$ found the prevalence of osteoporosis to be 33\% in men 50-59 aged years and $75 \%$ in men aged at least 80 years. Kanaji and colleagues $^{56}$ followed 23 elderly men with leprosy randomized to $2.5 \mathrm{mg}$ daily oral risedronate or placebo and found a significant reduction in urinary N-telopeptides and a significant increase in lumbar spine BMD at six and 12 months (See Table 2). Though there was a low incidence of vertebral fractures observed, the treatment group experienced fewer (ARR 1.06\%).

Risedronate is approved in the US for the treatment of osteoporosis in men.

\section{Limitations of oral therapy}

Because of their relative ease of use and low cost of generic alendronate, oral bisphosphonates have become mainstays of osteoporosis pharamacotherapy. Yet oral dosing is poorly absorbed, may worsen gastrointestinal toxicities, and side effects can decrease patient compliance. Esophageal injury may occur in patients on oral bisphosphonates, though randomized trials have failed to show significant association. Even in patients who strictly adhere to recommended use directions, case reports have shown oral alendronate has the potential to cause erosive esophagitis, esophageal or gastric ulcers and esophageal strictures. ${ }^{57}$ Recent reports of oral bisphosphonate-associated esophageal carcinoma have emerged. ${ }^{58}$ A meta-analysis of 76 randomized controlled trials of osteoporosis drug trials found that esophageal ulcerations and complications such as perforation and hemorrhage were reported in trials of all bisphosphonates except zoledronic acid. ${ }^{59}$ Other gastrointestinal symptoms related to oral bisphosphonates include pyrosis, dyspepsia, abdominal pain, nausea, and vomiting.

Long-term compliance with oral bisphosphonate therapy is low, and patients most commonly cite adverse drug effects as the reason for stopping therapy. ${ }^{60,61}$ One systematic review of seven observational studies of bisphosphonate compliance as measured by patient surveys indicates that the discontinuation rate at one year of daily dosing ranged 19\%-29\%. In the study that included men, the rate was $22 \%$. However, when compliance is measured by administrative data, the discontinuation rate was $68 \%$ for daily dosing and $56 \%$ for weekly dosing. Moreover, $76 \%$ patients had at least some interruption in bisphosphonate therapy during the first year of therapy. ${ }^{61}$ The costs of bisphosphonate noncompliance are high. Patients who are less than $66 \%$ compliant with osteoporosis medications have significantly lower increases in BMD. ${ }^{62}$ In an analysis of insurance claims databases involving 35,537 women prescribed bisphosphonates, only $43 \%$ women filled at least $80 \%$ of their prescriptions. However, the medication-compliant women had $37 \%$ fewer hip fractures at 24 months. ${ }^{63}$ 
Oral bisphosphonates are poorly absorbed, and dietary calcium, calcium supplements, and antacids further impede absorption. In order to optimize bioavailability, the patient should take the medication apart from food and all other medications for at least two hours before and 30 minutes after the dose. In order to minimize gastrointestinal side effects, the patient should take the medication with $6-8$ ounces of water and remain upright for 30 minutes thereafter. In a review of three observational trials of adherence to dosing instructions, up to $52 \%$ patients did not comply with at least one instruction. ${ }^{61}$ In one of the studies, $26 \%$ patients were not taking risedronate correctly and among these patients $28 \%$ experienced adverse effects. ${ }^{64}$

Factors associated with poorer bisphosphonate compliance include older age, male gender, nonwhite race, and greater number of comorbid conditions and nonosteoporosis medications. Compliance is improved with weekly vs daily dosing, and residence in a nursing home. ${ }^{61,65}$ Though not reported in these trials, compliance with the complex administration instructions is very likely also limited by cognitive dysfunction and physical debility.

\section{Ibandronate}

In an uncontrolled open label pilot, Lamy and colleagues ${ }^{66}$ enrolled 14 men with primary osteoporosis and either a prior osteoporotic fracture or a BMD at least 1.5 standard deviations below the age-matched mean. Subjects received $2 \mathrm{mg}$ IV ibandronate every three months. At two years, the authors noted significant reductions in osteocalcin and $\beta$-crosslaps assay for degradation products of type I collagen. During the two years of treatment, they showed significant increases in BMD at the lumbar spine, femoral neck, and total hip (See Table 2).

Another as yet unpublished trial of 168 men randomized to monthly oral ibandronate $150 \mathrm{mg}$ or placebo has the primary outcome of change in lumbar spine BMD. One year follow-up has been completed, and data will soon be presented (personal communication).

Ringe and colleagues ${ }^{67}$ studied 115 subjects with established glucocorticoid induced osteoporosis. The subjects required chronic prednisone use of at least $7.5 \mathrm{mg} /$ day for other systemic illnesses, most commonly COPD, rheumatoid arthritis, or polymyalgia rheumatica. Subjects were randomized to $2 \mathrm{mg}$ intravenous (IV) ibandronate every three months vs. daily oral alfacalcidol. Ibandronatetreated subjects experienced significantly greater increases in BMD at the spine and femoral neck, and improvements were progressive throughout the 36-month study period.
The ibandronate group had less lower back pain and less height loss. Though not powered to detect fracture difference, the study did show significantly fewer vertebral fractures in the ibandronate group (relative risk reduction [RRR] 62\%) and a nonsignificant trend toward fewer nonvertebral fractures (See Table 2).

Ibandronate is not approved in the US for the treatment of osteoporosis in men.

\section{Zoledronic acid}

Currently available IV nitrogen-containing bisphosphonates include pamidronate, ibandronate, and zoledronic acid. Zoledronic acid is the only IV bisphosphonate FDA-approved for the treatment of osteoporosis in men. It has the highest binding affinity to hydroxyapatite and the highest skeletal uptake $^{68}$ and is the most potent osteoclast inhibitor. Zoledronic acid is the only bisphosphonate with an indication for annual use.

\section{Evidence of benefit}

The HORIZON investigators studied zoledronic acid in secondary prevention of osteoporotic fractures. ${ }^{69}$ They randomized 2127 subjects ( $24 \%$ men) within 90 days of surgical repair of a hip fracture to receive $5 \mathrm{mg}$ annual IV zoledronic acid or placebo with first dose given within 90 days of hip fracture repair. At 36 months, the treated group had significantly increased bone density at the total hip and femoral neck compared to the placebo group. Over 1.9 years median follow-up, they observed significant decreases in any new fracture (139 vs 92, ARR 5.3\%), clinical vertebral fracture (39 vs 21, ARR 2.1\%), nonvertebral fracture (107 vs 79, ARR 3.1\%), and recurrent hip fracture (33 vs 23, ARR $1.5 \%$; see Table 2). Further, in this population at high risk for deadly recurrent fractures, the zoledronic acid-treated group experienced a survival advantage (RRR 28\%, ARR $3.7 \%){ }^{69}$ Men enjoyed a greater survival benefit than women (overall mortality ARR 6.4\%) and a marked reduction in cardiac-related deaths (RRR 62\%, RRR 4.8\%). ${ }^{70}$

Zoledronic acid has been approved in the US for treatment of osteoporosis in men on the basis of an as yet unpublished trial..$^{71}$ The study randomized 302 hypogonadal men to annual $5 \mathrm{mg}$ IV zoledronic acid or weekly $70 \mathrm{mg}$ oral alendronate. At two years, the zoledronic acid group had $6.1 \%$ increase in lumbar spine BMD compared to $6.2 \%$ increase in alendronate group. The all-cause mortality and serious adverse events were similar between treatment groups.

Poole and colleagues ${ }^{72}$ randomized 27 hemiplegic subjects within seven weeks after stroke zoledronic acid $4 \mathrm{mg}$ 
or placebo. The authors showed that treatment prevented significant bone loss at the hip. Without treatment, at one year the mean BMD of the total hip decreased $5.5 \%$ on the affected (hemiplegic) side and by $2.7 \%$ in the unaffected hip. With treatment, the mean BMD remained stable on the hemiplegic side and increased by $1 \%$ at the unaffected hip (see Table 2). 72\% subjects fell, but there were no fractures during the study period.

Human immunodeficiency virus (HIV) infection and antiretroviral therapy are associated with low bone density and osteoporosis. Brown and colleagues ${ }^{73}$ found that HIV-infected patients were 3.7 times as likely to have osteoporosis as uninfected individuals. Triant and colleagues ${ }^{74}$ reported that HIV-infected men and women have a significantly higher prevalence of hip, vertebral, and wrist fractures. Bolland and colleagues ${ }^{75}$ studied zoledronic acid in $43 \mathrm{HIV}+$ men with decreased bone mineral density receiving antiretroviral therapy. The men were randomized to $4 \mathrm{mg}$ IV annual zoledronic acid or placebo. Urinary N-telopeptide decreased by $61 \%$, and serum total alkaline phosphatase decreased by $21 \%$ from baseline by three months in the zoledronic acid-treated group. These values were significantly less than the untreated group, and the levels did not further decrease over the remaining two years in the study. In the zoledronic acid group, BMD increased significantly at the lumbar spine and total hip over the control group (see Table 2).

Studies confirm both clinical efficacy ${ }^{69,72,75}$ of annual zoledronic acid dosing and noninferiority compared to more frequent dosing, ${ }^{76}$ but it is not yet known how long a single dose of zoledronic acid can suppress bone turnover. Borba and colleagues ${ }^{77}$ showed persistent suppression of C-telopeptide and bone-specific alkaline phosphatase and persistent increase in bone mineral density at the lumbar spine and total hip at 18 months after a single dose of zoledronic acid. In an extension of a previous trial, Bolland and colleagues $^{78}$ showed persistence of drug effect in men at two years after a second annual dose of zoledronic acid in suppressing markers of bone turnover and increasing bone mineral density. Brown and colleagues ${ }^{79}$ studied 66 subjects with osteopenia after curative cancer treatment. All subjects received a single dose $4 \mathrm{mg}$ zoledronic acid and were followed for 36 months. Data were reported for men and women separately, and both showed durable decreases in urinary $\mathrm{NTx} / \mathrm{Cr}$ and increases in BMD at the spine and hip after at 36 months after a single zoledronic acid dose. Less frequent dosing regimens offer potential advantages such as reduced toxicity, greater convenience, improved compliance, and reduced cost. Though markers of bone turnover remain suppressed for more than one year, it is not known whether dosing zoledronic acid less than annually is as effective in terms of reduction in fracture risk.

\section{Comparing therapies for osteoporosis}

Few studies have made direct comparison of osteoporosis therapies in men. In theory, drugs such as teriparatide that stimulate bone formation may complement bisphosphonates (which inhibit osteoclast action) and provide even greater increases in BMD. Finkelstein and colleagues ${ }^{34,80}$ randomized 83 men with low bone mass to receive alendronate, teriparatide, or both daily. Subjects receiving alendronate started treatment at the beginning of the study, and subjects receiving teriparatide started at month 6. Sixty-three men completed the study. At 30 months, the authors found that teriparatide increased BMD at the lumbar spine and femoral neck significantly more than combination therapy, and combination therapy increased BMD at the lumbar spine and femoral neck significantly more than alendronate alone. ${ }^{34}$ The authors went on to show that marker of bone turnover such as serum N-telopeptide (NTX), osteocalcin, and amino-terminal propeptide of type 1 procollagen increased markedly upon starting teriparatide monotherapy and then declined toward baseline. With alendronate monotherapy, the markers of bone turnover decreased and remained stable. Combination therapy led to an initial decline in bone markers on alendronate alone followed by a rebound with teriparatide so that levels returned to baseline or above. Alendronate pretreatment blunted the treatment effect of teriparatide, ${ }^{80}$ and the authors conclude that alendronate impairs the ability of teriparatide to increase bone turnover or increase the BMD at the lumbar spine and the femoral neck in men.

Welch and colleagues ${ }^{81}$ retrospectively studied 149 men treated with testosterone, alendronate, or both for at least one year. Men in the testosterone group were referred for treatment of hypogonadism, and men in the alendronate group were referred for treatment of osteoporosis. Yet at baseline, the groups were similar in terms of age, weight, body mass index, and BMD at the lumbar spine and total hip. Compared with the baseline values, lumbar spine BMD increased significantly by $2.1 \%$ in the testosterone group, $2.6 \%$ in the alendronate group, and $2.5 \%$ in the group receiving combination therapy. There were no significant differences in BMD at the lumbar spine or total hip between groups, suggesting that the combination of testosterone and alendronate does not appear to be superior to either drug used alone.

A recently conducted, unpublished trial at our institution directly compares alendronate and zoledronic acid in 
the treatment of male osteoporosis. The investigators retrospectively reviewed the charts of 64 men: 26 received annual IV zoledronic acid $4 \mathrm{mg}$ and 38 received weekly oral alendronate $70 \mathrm{mg}$. At one year, they found no differences in BMD at the lumbar spine or femoral neck between groups (personal communication).

\section{Bisphosphonate use in bone loss due to androgen deprivation}

Prostate cancer becomes increasingly common as men age, and androgen deprivation therapy (ADT) for prostate cancer places men at uniquely high risk for osteoporosis and fracture. ADT, which may include orchiectomy or GnRH agonist therapy, markedly reduces circulating testosterone to prepubertal levels. In one prospective cohort study of 152 men with nonmetastatic prostate cancer including 30 on acute $\mathrm{ADT}<6$ months and 50 on chronic ADT $>6$ months, Greenspan and colleagues ${ }^{82}$ found that men starting ADT experienced significant reductions in bone mineral density ( $2.5 \%$ total hip, $4.0 \%$ spine) by 12 months follow-up. When compared to healthy age-matched controls and to patients with prostate cancer but not on ADT, the acute ADT had fiveto tenfold increased bone density loss at multiple skeletal sites. When compared to men on chronic ADT, it appeared that the greatest bone loss occurred in the first 12 months of ADT. Shananian and colleagues ${ }^{83}$ measured fracture rates on 50,613 men with the diagnosis of prostate cancer. Among the men that survived five years after diagnosis, they found that $19.4 \%$ men on ADT experienced a fracture, as compared to $12.6 \%$ those not receiving ADT $(\mathrm{p}<0.001)$. Furthermore, fractures at every site, fractures requiring hospitalization, and diagnosis of osteoporosis were all significantly increased in patients receiving ADT.

Smith and colleagues ${ }^{84}$ studied 47 men with advanced or recurrent nonmetastatic prostate cancer. The authors randomized the subjects to receive pamidronate $60 \mathrm{mg}$
IV every 12 weeks plus leuprolide or leuprolide alone. All measured biomarkers of bone turnover; osteocalcin, bone-specific alkaline phosphatase, urinary deoxypyridinoline, and urinary N-telopeptide were significantly reduced in the pamidronate group. Treatment with pamidronate prevented the significant reductions in BMD experienced by the leuprolide-only group. They reported an absolute difference between groups in BMD at the lumbar spine and total hip, but there was no change in either group at the femoral neck (see Table 3 ).

Greenspan and colleagues ${ }^{85}$ studied 112 men with nonmetastatic prostate cancer receiving ADT in a partial-crossover design. Subjects were randomly assigned to receive alendronate $70 \mathrm{mg}$ weekly or placebo at enrollment. At 12 months, all subjects in the placebo group crossed over to the alendronate group, and subjects in the alendronate group were rerandomized to continue alendronate or placebo. At two years, the subjects randomized to alendronate treatment both times had the greatest decrease in $\mathrm{N}$-telopeptide, C-telopeptide, type 1 procollagen, and bone-specific alkaline phosphatase. The alendronate-alendronate group also had the highest BMD at the lumbar spine, total hip, femoral neck, and distal 1/3 radius. Fractures were not studied. The investigators found that a second year of alendronate resulted in continued improvements in bone density and decreases in bone markers.

Delay in alendronate initiation (as in the placeboalendronate group) resulted in lower bone density and decreased suppression of bone markers compared to early treatment. ${ }^{85}$ Discontinuation of alendronate (in the alendronate-placebo group) resulted in increases in markers of bone turnover and significantly decreased BMD at all skeletal sites compared to the alendronate-alendronate arm. The authors also performed post-hoc analysis of changes in BMD depending on length of ADT prior to alendronate treatment. They found that men who received ADT for less than 36 months experienced significantly greater increases

Table 3 Trials in prostate cancer with ADT

\begin{tabular}{|c|c|c|c|c|c|c|c|c|}
\hline \multirow[t]{2}{*}{ Citation } & \multirow[t]{2}{*}{ Drug } & \multirow{2}{*}{$\begin{array}{l}\text { Study } \\
\text { design }\end{array}$} & \multirow[t]{2}{*}{$\mathbf{N}$} & \multirow{2}{*}{$\begin{array}{l}\text { Duration } \\
\text { (mo) }\end{array}$} & \multirow{2}{*}{$\begin{array}{l}\text { Avg } \\
\text { age }\end{array}$} & \multicolumn{3}{|c|}{$\Delta \%$ increase BMD } \\
\hline & & & & & & $\mathbf{H}$ & $\mathbf{F N}$ & LS \\
\hline Smith et $\mathrm{al}^{84}$ & pamidronate & RCT & 47 & 48 wk & 67 & $2.0 \%$ & NS & $3.8 \%$ \\
\hline Greenspan et $a^{85}$ & alendronate & $\mathrm{RCT}$ & 112 & 12 & 71.4 & & & \\
\hline Ryan et al ${ }^{86}$ & zoledronic acid & $\mathrm{RCT}$ & 120 & 12 & 72 & $3.8 \%$ & $3.6 \%$ & $6.7 \%$ \\
\hline Smith et $\mathrm{al}^{87}$ & zoledronic acid & $\mathrm{RCT}$ & 106 & 12 & 70.7 & $3.9 \%$ & $3.3 \%$ & $7.8 \%$ \\
\hline Michaelson et $\mathrm{a}^{88}$ & zoledronic acid & $\mathrm{RCT}$ & 40 & 12 & 65.5 & $2.6 \%$ & $2.1 \%$ & $7.1 \%$ \\
\hline Ryan et al ${ }^{89}$ & zoledronic acid & $\mathrm{RCT}$ & 42 & 12 & 65 & & $4.2 \%$ & $7.1 \%$ \\
\hline
\end{tabular}




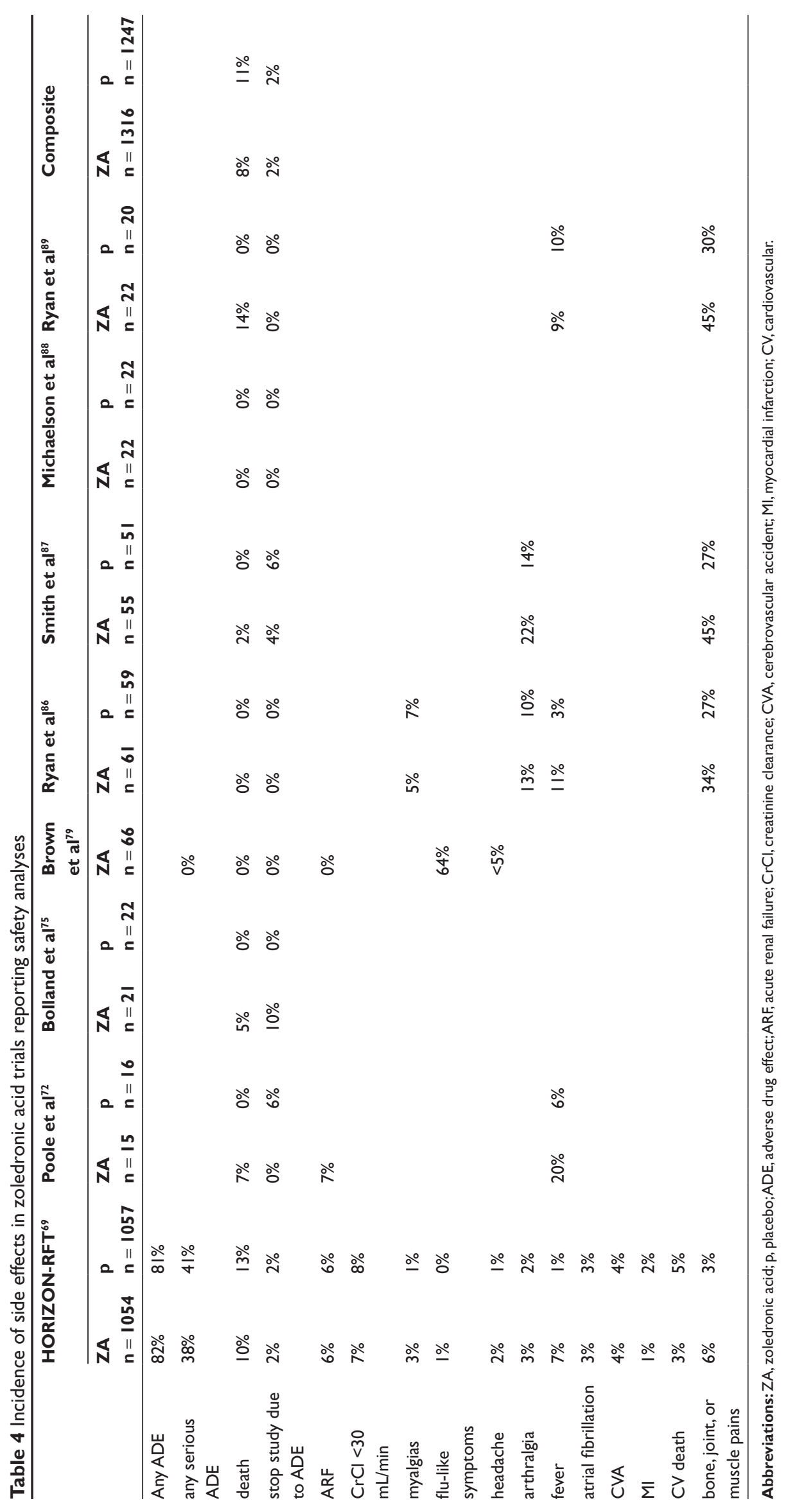


in BMD on alendronate than men who received ADT for 36 months or more.

Ryan and colleagues ${ }^{86}$ studied 120 men with nonmetastatic prostate cancer on ADT for 12 months or less prior to enrollment. Subjects were randomized to zoledronic acid $4 \mathrm{mg}$ IV every three months or placebo and stratified by duration of ADT (less than six months or 6-12 months). Treated subjects had significant reductions in urinary N-telopeptide and serum bone-specific alkaline phosphatase compared to the placebo group and significant improvements in BMD at one year at the femoral neck, total hip, and lumbar spine (see Table 3). The results were not differentiated based on duration of ADT. Taken together, these studies ${ }^{85,86}$ support initiation of bisphosphonates within one year of ADT and continued treatment for greater than one year in men on ADT.

Smith and colleagues ${ }^{87}$ studied zoledronic acid in 106 men with nonmetastatic prostate cancer beginning ADT. Subjects were randomized to zoledronic acid $4 \mathrm{mg}$ IV every three months or placebo. At one year, the placebo group lost 2\%-3\% BMD at the lumbar spine, femoral neck, and total hip. By comparison, treated group had gains in BMD and showed significantly greater BMD at each skeletal site (see Table 3).

Michaelson and colleagues ${ }^{88}$ randomized 40 men with nonmetastatic prostate cancer on ADT and osteoporosis (T $<-2.5$ ), to receive a single dose $4 \mathrm{mg}$ IV zoledronic acid or placebo. Subjects who received zoledronic acid had significant reductions in N-telopeptide and bone-specific alkaline phosphatase at 12 months as well as significantly greater BMD at the lumbar spine, total hip and femoral neck (see Table 3).

Ryan and colleagues ${ }^{89}$ studied 42 men with hormonesensitive prostate cancer with and without metastasis on ADT less than one year. The subjects were randomized to zoledronic acid $4 \mathrm{mg}$ IV every three months or placebo. Skeletal sites with metastasis were excluded from DEXA measurement of BMD. At 12 months, subjects treated with zoledronic acid had significantly greater decreases in N-telopeptide and bone-specific alkaline phosphatase. Men with bone metastases had significantly higher baseline $\mathrm{N}$-telopeptide and bone-specific alkaline phosphatase, but the improvements in suppression of these markers of bone turnover was independent of the presence of metastases. Treated subjects also had significantly greater BMD at the lumbar spine and femoral neck (see Table 3).

\section{Raloxifene in ADT}

Estrogen deficiency plays a significant role in bone loss in men. Doran and colleagues ${ }^{90}$ randomized 50 elderly men without osteoporosis to receive the selective estrogen receptor modulator (SERM) raloxifene $60 \mathrm{mg}$ per day or placebo. At six months, the treated group overall showed no effect in decreasing urinary N-telopeptide (NTx) excretion. However, in the subset of men with baseline low estradiol levels (mean $22 \mathrm{pg} / \mathrm{mL}$ ), raloxifene treatment decreased urinary NTx. Smith and colleagues ${ }^{91}$ found a similar treatment effect in 48 men with nonmetastatic prostate cancer on $\mathrm{GnRH}$ agonist therapy treated with raloxifene $60 \mathrm{mg}$ daily. The average estradiol level was $5 \mathrm{pg} / \mathrm{mL}$. At 12 months, the raloxifene-treated group had significantly decreased serum amino-terminal propeptide of type I collagen and significantly increased BMD in the total hip $(+1.1 \% \mathrm{vs}-2.6 \%$, p $<0.001)$ and a nonsignificant trend to increased density in the lumbar spine $(+1.0 \%$ vs $-1.0 \%, \mathrm{p}=0.07)$.

Raloxifene is not approved in the US for the treatment of osteoporosis in men.

\section{Indications}

Zoledronic acid (Reclast) is approved in the US as an annual IV infusion of $5 \mathrm{mg}$ to treat osteoporosis in men or women and to treat Paget's disease. Zoledronic acid is also marketed as a $4 \mathrm{mg}$ dose $\left(\right.$ Zometa $\left.^{\circledR}\right)$ IV infusion every 3-4 weeks to treat hypercalcemia of malignancy, multiple myeloma, and bone metastases from all solid tumors including lung and prostate cancer.

Zoledronic acid is the only IV bisphosphonate approved in the US for the treatment of osteoporosis in men.

\section{Adverse drug effects}

Eight trials of zoledronic acid including men for nonmetastatic bone loss have been published, ${ }^{69,72,75,79,86-89}$ and all eight reported basic safety data such as number of subjects who died or withdrew because of adverse events. Six of these studies ${ }^{69,72,75,86,87,89}$ reported more extensive safety analyses. In the largest of these trials, ${ }^{69}$ there was no association between zoledronic acid and early study withdrawal due to adverse event.

Prior studies ${ }^{92}$ have identified five typical infusion-related symptoms that occur in more than $30 \%$ subjects receiving a first dose zoledronic acid within three days of drug administration. These symptoms include myalgias, influenza-like symptoms, fever, arthralgias, and headache. The reported rates of these symptoms in the eight trials described are generally lower than in prior studies, though myalgias and fever were significantly more common in the zoledronic acid-treated subjects. ${ }^{69}$ These symptoms are typically mild, resolve within 3-4 days, and occur less frequently with 
successive infusions of the drug. Patients should be pretreated with acetominophen.

Many symptoms were variably described among the studies. The frequency of a composite of reports of bone or back pain, myalgias, and arthralgias was 9\% among zoledronic acid-treated subjects vs 5\% among those receiving placebo. Currently the US FDA is investigating reports of "severe and sometimes incapacitating bone, joint, and/or muscle pains" in chronic use of bisphosphonates as a class. ${ }^{93}$

Infusing zoledronic acid over at least 15 minutes reduces the risk of renal toxicity. In each of the studies cited, zoledronic acid was given over 15 minutes, and there was no significant difference in rates of rise of serum creatinine $>0.5 \mathrm{mg} / \mathrm{dL} .{ }^{69,72}$ Zoledronic acid $5 \mathrm{mg}$ dose $\left(\right.$ Reclast $\left.^{\circledR}\right)$ is not recommended for patients with creatinine clearance $<35 \mathrm{~mL} / \mathrm{min}$ due to lack of experience in this patient population. Zoledronic acid $4 \mathrm{mg}$ $\left(\right.$ Zometa $\left.^{\circledR}\right)$ is recommended at full dose for patients with estimated creatinine clearance $>60 \mathrm{~mL} / \mathrm{min}$ with dose reductions for creatinine clearances between $30-60 \mathrm{~mL} / \mathrm{min}$. Because of the lack of clinical data to date, it is not recommended for use in patients with creatinine clearance $<30 \mathrm{~mL} / \mathrm{min}$. Asymptomatic and generally transient hypocalcemia and hypophosphatemia have been reported independent of baseline $25-\mathrm{OH}$ vitamin D levels. ${ }^{72}$

Osteonecrosis of the jaw (ONJ) is a serious complication of bisphosphonate use defined as an area of exposed bone in the maxillofacial region that does not heal within eight weeks after identification by a health care provider. ${ }^{94}$ It appears that potency of the bisphosphonate and duration of exposure to the drug increase the risk of ONJ. Patient factors which increase the risk of ONJ include cancer diagnosis, chemotherapy, glucocorticoid use, tobacco use, and pre-existing dental and periodontal disease. Although the true incidence of ONJ is unknown, recent expert consensus ${ }^{94}$ estimates $1 / 10,000$ to less than $1 / 100,000$ patient-years in patients receiving oral bisphosphonate treatment for osteoporosis.

In the above eight zoledronic acid trials including 2563 subjects studied over 6960 patient-years, not a single case of ONJ was reported. However, these numbers must be interpreted with caution in that cumulative exposure and duration of follow-up (average 1-2 years) may not be enough to detect ONJ. The incidence of ONJ in patients receiving IV zoledronic acid for treatment of malignancy is much higher, as high as $1 \%-10 \% .{ }^{94}$ Boonyapakorn and colleagues $^{95}$ prospectively studied 80 patients receiving monthly IV zoledronic acid or pamidronate for cancer diagnosis, most commonly multiple myeloma and breast cancer. Using dental radiographs and intraoral examinations, they found that $22(28 \%)$ patients developed ONJ after bisphosphonate exposure. The mean time from exposure to ONJ in the zoledronic acid-treated patients was 26 months. Initiation of bisphosphonate therapy need not be delayed for routine dental work, but patients should be counseled on the importance of dental hygiene and recommended to have regular dental visits for routine care.

Black and colleagues ${ }^{92}$ reported an increased incidence of serious atrial fibrillation in women treated with zoledronic acid infusion, and Heckbert and colleagues ${ }^{96}$ found greater likelihood of prior alendronate use among 719 women with confirmed new onset atrial fibrillation. In contrast, Lyles and colleagues ${ }^{69}$ found no association between zoledronic acid and atrial fibrillation, stroke, myocardial infarction, or death from cardiovascular causes. Sørensen and colleagues ${ }^{97}$ retrospectively studied 13,586 Danish women with atrial fibrillation and atrial flutter and found that alendronate and etidronate use was not more common among affected patients than population controls (adjusted relative risk among women with current bisphosphonate use 0.95). US FDA review of 19,687 bisphosphonate-treated patients found no association with atrial fibrillation. ${ }^{98}$ Whether bisphosphonate use predisposes a patient to atrial fibrillation remains an open question. However, this small potential risk must be considered in relation to potentially large benefits in terms of fracture reduction and survival.

\section{Summary}

Osteoporosis and low bone mass are under-recognized and undertreated in men. As the population ages, the rates of osteoporosis and osteoporotic fractures are expected to rise. Men with prior fragility fractures, older men, and men with lower BMD are at highest risk of fracture. Men with glucocorticoid use, hypogonadism, tobacco or heavy alcohol intake, vitamin D deficiency, or androgen deprivation therapy for prostate cancer are also at increased risk for osteoporosis. Laboratory evaluation for secondary causes of osteoporosis and radiographic screening for occult vertebral fractures in men with height loss are essential parts of the workup of men with osteoporosis. All men should receive adequate dietary calcium and vitamin D. Bisphosphonates are potent antiresorptive agents that inhibit osteoclast activity, suppress in vivo markers of bone turnover, and decrease fracture risk in patients at high risk of fracture. Intravenous zoledronic acid may be a preferable alternative to oral bisphosphonate therapy in patients with cognitive dysfunction, the inability to sit upright, or significant gastrointestinal pathology. 


\section{Disclosure}

The authors report no conflicts of interest in this work.

\section{References}

1. NIH Consensus Development Panel on Osteoporosis Prevention, Detection, and Therapy. Osteoporosis prevention, diagnosis, and therapy. JAMA. 2001;285:785-795.

2. National Osteoporosis Foundation Advocacy News and Updates. The state of osteoporosis and low bone mass in the US. 2009. Cited 2009 Feb 18 Available from: http://www.nof.org/advocacy/prevalence/index.htm.

3. Jones G, Nguyen T, Sambrook PN, Kelly PJ, Gilbert C, Eisman JA. Symptomatic fracture incidence in elderly men and women: the Dubbo Osteoporosis Epidemiology Study (DOES). Osteoporosis Int. 1994;4:277-282.

4. Winner SJ, Morgan CA, Evans JG. Perimenopausal risk of falling and incidence of distal forearm fracture. BMJ. 1989;298(6686):1486-1488.

5. Office of the Surgeon General. The burden of bone disease. In: Bone health and osteoporosis: A report of the Surgeon General. 2004. Cited 2009 Jan 31. Available from: http://www.surgeongeneral.gov/library/ bonehealth/chapter_5.html.

6. Leibson CL, Tosteson AN, Gabriel SE, Ransom JE, Melton LJ. Mortality, disability, and nursing home use for persons with and without hip fracture: a population-based study. J Am Geriatr Soc. 2002;50(10):1644-1650.

7. Center JR, Nguyen TV, Schneider D, et al. Mortality after all major types of osteoporotic fractures in men and women: an observational study. Lancet. 1999;76:235-242.

8. Magaziner J, Fredman L, Hawkes W, et al. Changes in functional status attributable to hip fracture: a comparison of hip fracture patients to community-dwelling aged. Am J Epidemiol. 2003;157(11): 1023-1031.

9. Chrischilles EA, Butler CD, Davis CS, Wallace RB. A model of lifetime osteoporosis impact. Arch Intern Med. 1991;151(10):2026-2032.

10. Tosteson AN. Economic impact of fractures. In: Orwoll ES, editor. Osteoporosis in men: The effects of gender on skeletal health. San Diego: Academic Press; 1999. p. 15-27.

11. Hasserius R, Karlsson MK, Jonsson B, et al. Long-term morbidity and mortality after a clinically diagnosed vertebral fracture in the elderly: a 12- and 22-year follow-up of 257 patients. Calcif Tissue Int. 2005;76:235-242.

12. Lewis CE, Ewing SK, Taylor BC, et al; for the Osteoporotic Fractures in Men (MrOS) Study Research Group. Predictors of non-spine fracture in elderly men: the MrOS study. J Bone Miner Res. 2007;22(2): 211-219.

13. Nguyen TV, Eisman JA, Kelly PA, et al. Risk factors for osteoporotic fractures in elderly men. Am J Epidemiol. 1996;144:255-263.

14. Gruntmanis U. Male osteoporosis: deadly, but ignored. Am J Med Sci. 2007;333(2):85-92.

15. Kelepouris N, Harper KD, Gannon F, Kaplan FS, Haddad JG. Severe osteoporosis in men. Ann Intern Med. 1995;123(6):452-460.

16. Orwoll ES, Klein RF. Osteoporosis in men. Endocr Rev. 1995;16(1): 87-116.

17. World Health Organization Collaborating Centre for Metabolic Bone Diseases. FRAX ${ }^{\circledR}$ WHO Fracture Risk Assessment Tool. Sheffield, UK. World Health Organization Collaborating Centre for Metabolic Bone Diseases, University of Sheffield, UK. 2009. Cited 2009 Feb 13. Available from: http://www.shef.ac.uk/FRAX/index.htm.

18. Khosla S, Amin S, Orwoll E. Osteoporosis in men. Endocr Rev 2008;29(4):441-464

19. Ebeling PR. Osteoporosis in men. N Engl J Med. 2008;358:1474-1482.

20. Sherrington C, Whitney JC, Lord SR, Herbert RD, Cumming RG, Close JC. Effective exercise for the prevention of falls: a systematic review and meta-analysis. J Am Geriatr Soc. 2008;56(12):2234-2243.

21. Martyn-St James M, Carroll S. High-intensity resistance training and postmenopausal bone loss: a meta-analysis. Osteoporos Int. 2006;17(8):1225-1240.
22. Larsen ER, Mosekilde L, Foldspang A. Vitamin D and calcium supplementation prevents osteoporotic fractures in elderly community dwelling residents: a pragmatic population-based 3-year intervention study. J Bone Miner Res. 2004;19(3):370-378.

23. Trivedi DP, Doll R, Khaw KT. Effect of four monthly oral vitamin D3 (cholecalciferol) supplementation on fractures and mortality in men and women living in the community: randomised double blind controlled trial. BMJ. 2003;326(7387):469.

24. Dawson-Hughes B, Harris SS, Krall EA, Dallal GE. Effect of calcium and vitamin D supplementation on bone density in men and women 65 years of age or older. N Engl J Med. 1997;337(10):670-676.

25. Grant AM, Avenell A, Campbell MK, et al; for RECORD Trial Group. Oral vitamin D3 and calcium for secondary prevention of low-trauma fractures in elderly people (Randomised Evaluation of Calcium Or vitamin D, RECORD): a randomised placebo-controlled trial. Lancet. 2005;365(9471):1621-1628.

26. National Osteoporosis Foundation. Clinician's guide to prevention and treatment of osteoporosis. 2009. Cited 2009 Feb 18. Available from: http://www.nof.org/professionals/cliniciansguide_form.asp.

27. Trovas GP, Lyritis GP, Galanos A, Raptou P, Constantelou E. A randomized trial of nasal spray salmon calcitonin in men with idiopathic osteoporosis: effects on bone mineral density and bone markers. J Bone Miner Res. 2002;17(3):521-527.

28. Toth E, Csupor E, Meszaros S, et al. The effect of intranasal salmon calcitonin therapy on bone mineral density in idiopathic male osteoporosis without vertebral fractures - an open label study. Bone. 2005;36(1): 47-51

29. Wang C, Cunningham G, Dobs A, et al. Long-term testosterone gel (AndroGel) treatment maintains beneficial effects on sexual function and mood, lean and fat mass, and bone mineral density in hypogonadal men. J Clin Endocrinol Metab. 2004;89(5):2085-2098.

30. Snyder PJ, Peachey H, Berlin JA, et al. Effects of testosterone replacement in hypogonadal men. J Clin Endocrinol Metab. 2000;85(8): 2670-2677.

31. Snyder PJ, Peachey H, Berlin JA, et al. Effect of testosterone treatment on bone mineral density in men over 65 years of age. J Clin Endocrinol Metab. 1999;84(6):1966-1972.

32. Katznelson L, Finkelstein JS, Schoenfeld DA, Rosenthal DI, Anderson EJ, Klibanski A. Increase in bone density and lean body mass during testosterone administration in men with acquired hypogonadism. J Clin Endocrinol Metab. 1996;81(12):4358-4365.

33. Anderson FH, Francis RM, Peaston RT, Wastell HJ. Androgen supplementation in eugonadal men with osteoporosis: effects of six months' treatment on markers of bone formation and resorption. J Bone Miner Res. 1997;12(3):472-478.

34. Finkelstein JS, Hayes A, Hunzelman JL, Wyland JJ, Lee H, Neer RM. The effects of parathyroid hormone, alendronate, or both in men with osteoporosis. N Engl J Med. 2003;349:1216-1226.

35. Saag KG, Shane E, Boonen S, et al. Teriparatide or alendronate in glucocorticoid-induced osteoporosis. $N$ Engl J Med. 2007;357: 2028-2039.

36. Russell RG. Bisphosphonates: from bench to bedside. Ann NY Acad Sci. 2006;1068:367-401.

37. Dunford JE, Thompson K, Coxon FP, et al. Structure-activity relationships for inhibition of farnesyl diphosphate synthase in vitro and inhibition of bone resorption in vivo by nitrogen-containing bisphosphonates. J Pharmacol Exp Ther. 2001;296(2):235-242.

38. Smith MR. Bisphosphonates to prevent osteoporosis in men receiving androgen deprivation therapy for prostate cancer. Drugs Aging 2003;20(3)175-183.

39. Drake MT, Clarke BL, Khosla S. Bisphosphonates: mechanism of action and role in clinical practice. Mayo Clin Proc. 2008;83(9): 1032-1045

40. Reid IR. Bisphosphonates: new indications and methods of administration. Curr Opin Rheumatol. 2003;15(4):458-463.

41. Hall A. Rho GTPases and the actin cytoskeleton. Science. 1998; 279(5350):509-514. 
42. Weinstein RS, Roberson PK, Manolagas SC. Giant osteoclast formation and long-term oral bisphosphonate therapy. $N$ Engl J Med. 2009;360:53-62.

43. Ryan PJ, Blake GM, Davie M, Haddaway M, Gibson T, Fogelman I. Intermittent oral disodium pamidronate in established osteoporosis: a 2 year double-masked placebo-controlled study of efficacy and safety. Osteoporos Int. 2000;11(2):171-176.

44. Brumsen C, Papapoulos SE, Lips P, et al. Daily oral pamidronate in women and men with osteoporosis: a 3-year randomized placebocontrolled clinical trial with a 2-year open extension. J Bone Miner Res. 2002;17(6):1057-1064.

45. Boutsen Y, Jamart J, Esselinckx W, Devogelaer JP. Primary prevention of glucocorticoid-induced osteoporosis with intravenous pamidronate and calcium: a prospective controlled 1-year study comparing a single infusion, an infusion given once every 3 months, and calcium alone. J Bone Miner Res. 2001;16(1):104-112.

46. Ho YV, Frauman AG, Thomson W, Seeman E. Effects of alendronate on bone density in men with primary and secondary osteoporosis. Osteoporos Int. 2000;11(2):98-101.

47. Orwoll E, Ettinger M, Weiss S, et al. Alendronate for the treatment of osteoporosis in men. N Engl J Med. 2000;343:604-610.

48. Ringe JD, Dorst A, Faber H, Ibach K. Alendronate treatment of established primary osteoporosis in men: 2-year results of a prospective, comparative, two-arm study. Rheumatol Int. 2004;24:110-113.

49. Sawka AM, Papaioannou A, Adachi JD, Gafni A, Hanley DA, Thabane L. Does alendronate reduce the risk of fracture in men? A meta-analysis incorporating prior knowledge of anti-fracture efficacy in women. $B M C$ Musculoskelet Disord. 2005;6:39.

50. Ringe JD, Faber H, Farahmand P, Dorst A. Efficacy of risedronate in men with primary and secondary osteoporosis: results of a 1-year study. Rheumatol Int. 2006;26:427-431.

51. Boonen S, Orwoll ES, Wenderoth D, Stoner KJ, Eusebio R, Delmas PD. Once-weekly risedronate in men with osteoporosis: results of a 2-year, placebo-controlled, double-blind, multicenter study. J Bone Miner Res. 2009;24:719-725.

52. Reid DM, Adami S, Devogelaer J-P, Chines AA. Risedronate increases done density and reduces vertebral fracture risk within one year in men on corticosteroid therapy. Calcif Tissue Int. 2001;69:242-247.

53. Sato Y, Iwamoto J, Kanoko T, Satoh K. Risedronate sodium therapy for prevention of hip fracture in men 65 years or older after stroke. Arch Intern Med. 2005;165:1743-1748.

54. Leal AM, Foss NT. Endocrine dysfunction in leprosy. Eur J Clin Microbiol Infect Dis. 2009;28:1-7.

55. Ishikawa S, Ishikawa A, Yoh K, Tanaka H, Fujiwara M. Osteoporosis in male and female leprosy patients. Calcif Tissue Int. 1999;64: 144-147.

56. Kanaji A, Higashi M, Namisato M, Nishio M, Ando K, Yamada H. Effects of risedronate on lumbar bone mineral density, bone resorption, and incidence of vertebral fracture in elderly male patients with leprosy. Lepr Rev. 2006;77:147-153.

57. Parfitt JR, Driman DK. Pathological effects of drugs on the gastrointestinal tract: a review. Hum Pathol. 2007;38,527-536.

58. Wysowski DK. Reports of esophageal cancer with oral bisphosphonate use. $N$ Engl J Med. 2009;360(1):89-90.

59. MacLean C, Newberry S, Maglione M, et al. Systematic review: comparative effectiveness of treatments to prevent fractures in men and women with low bone density or osteoporosis. Ann Intern Med. 2008;148:197-213.

60. Tosteson AN, Grove MR, Hammond CS, et al. Early discontinuation of treatment for osteoporosis. Am J Med. 2003;115(3):209-216.

61. Papaioannou A, Kennedy CC, Dolovich L, Lau E, Adachi JD. Patient adherence to osteoporosis medications: problems, consequences and management strategies. Drugs Aging. 2007;24(1):37-55.

62. Yood RA, Emani S, Reed JI, Lewis BE, Charpentier M, Lydick E. Compliance with pharmacologic therapy for osteoporosis. Osteoporos Int. 2003;14:965-968.
63. Siris ES, Harris ST, Rosen CJ, et al. Adherence to bisphosphonate therapy and fracture rates in osteoporotic women: relationship to vertebral and nonvertebral fractures from 2 US claims databases. Mayo Clin Proc. 2006;81(8):1013-1022.

64. Hamilton B, McCoy K, Taggart H. Tolerability and compliance with risedronate in clinical practice. Osteoporos Int. 2003;14:259-262.

65. Solomon DH, Avorn J, Katz JN, et al. Compliance with osteoporosis medications. Arch Intern Med. 2005;165:2414-2419.

66. Lamy O, Sandini L, Pache I, Fatio S, Burnand J, Burckhardt P. Intravenous ibandronate in men with osteoporosis: an open pilot study over 2 years. J Endocrinol Invest. 2003;26(8):728-732.

67. Ringe JD, Dorst A, Faber H, Ibach K, Sorenson F. Intermittent intravenous ibandronate injections reduce vertebral fracture risk in corticosteroid-induced osteoporosis: results from a long-term comparative study. Osteoporos Int. 2003;14:801-807.

68. Nancollas GH, Tang R, Phipps RJ, et al. Novel insights into actions of bisphosphonates on bone: differences in interactions with hydroxyapatite. Bone. 2006;38:617-627.

69. Lyles KW, Colón-Emeric CS, Magaziner JS, et al; for the HORIZON Recurrent Fracture Trial. Zoledronic acid and clinical fractures and mortality after hip fracture. N Engl J Med. 2007;357: 1799-1809.

70. Colón-Emeric C, Mesenbrink P, Lyles K, et al. Potential mediators of the reduction in mortality with zoledronic acid after hip fracture [abstract]. Presented at the American Society for Bone Mineral Research meeting Sept 13, 2008.

71. Novartis Pharmaceuticals. Reclast prescribing information. March 2009. Cited 2009 May 18. Available from: http://dailymed.nlm.nih. gov/dailymed/archives/fdaDrugInfo.cfm? archiveid=8476.

72. Poole KE, Loveridge N, Rose CM, Warburton EA, Reeve J. A single infusion of zoledronate prevents bone loss after stroke. Stroke. 2007;38:1519-1525.

73. Brown TT, Qaqish RB. Antiretroviral therapy and the prevalence of osteopenia and osteoporosis: a meta-analytic review. AIDS. 2006;20(17):2165-2174.

74. Triant VA, Brown TT, Lee H, Grinspoon SK. Fracture prevalence among human immunodeficiency virus (HIV)-infected versus non-HIVinfected patients in a large U.S. healthcare system. J Clin Endocrinol Metab. 2008;93(9):3499-3504.

75. Bolland MJ, Grey AB, Horne AM, et al. Annual zoledronate increases bone density in highly active antiretroviral therapy-treated human immunodeficiency virus-infected men: a randomized controlled trial. J Clin Endocrinol Metab. 2007;92:1283-1288.

76. Reid IR, Brown JP, Burckhardt P, et al. Intravenous zoledronic acid in postmenopausal women with low bone mineral density. $N$ Engl J Med. 2002;346:653-661.

77. Borba VZ, Paz-Filho G, Kulak CA, Seibel MJ, Bilezikian JP. Bone turnover 18 months after a single intravenous dose of zoledronic acid. Int J Clin Pract. 2007;61(6):1058-1062.

78. Bolland MJ, Grey AB, Horne AM, et al. Effects of intravenous zoledronate on bone turnover and BMD persist for at least 24 months. J Bone Miner Res. 2008;23:1304-1308.

79. Brown JE, Ellis SP, Lester JE, et al. Prolonged efficacy of a single dose of the bisphosphonate zoledronic acid. Clin Cancer Res. 2007;13(18):5406-5410.

80. Finkelstein JS, Leder BZ, Burnett SM, et al. Effects of teriparatide, alendronate, or both on bone turnover in osteoporotic men. J Clin Endocrinol Metab. 2006;91(8):2882-2887.

81. Welch BJ, Denke MA, Kermani A, Adams-Huet B, Gazmen NM, Gruntmanis U. Comparison of testosterone, alendronate, and a combination of both therapies in men with low bone mineral density. J Invest Med. 2007;55(4):168-173.

82. Greenspan SL, Coates P, Sereika SM, Nelson JB, Trump DL, Resnick NM. Bone loss after initiation of androgen deprivation therapy in patients with prostate cancer. J Clin Endocrinol Metab. 2005;90: 6410-6417. 
83. Shahinian VB, Kuo Y-F, Freeman JL, Goodwin JS. Risk of fracture after androgen-deprivation for prostate cancer. $N$ Engl J Med. 2005;352:154-164.

84. Smith MR, McGovern FJ, Zietman AL, et al. Pamidronate to prevent bone loss during androgen-deprivation therapy for prostate cancer. N Engl J Med. 2001;345:948-955.

85. Greenspan SL, Nelson JB, Trump DL, et al. Skeletal health after continuation, withdrawal, or delay of alendronate in men with prostate cancer undergoing androgen-deprivation therapy. J Clin Oncol. 2008;26:4426-4434.

86. Ryan CW, Huo D, Demers LM, Beer TM, Lacerna LV for the Zometa US05 Investigators. Zoledronic acid initiated during the first year of androgen deprivation therapy increases bone mineral density in patients with prostate cancer. J Urol. 2006;176:972-978.

87. Smith MR, Eastham J, Gleason DM, Shasha D, Tchekmedyian S, Zinner N. Randomized controlled trial of zoledronic acid to prevent bone loss in men receiving androgen deprivation therapy for nonmetastatic prostate cancer. J Urol. 2003;169:2008-2012.

88. Michaelson MD, Kaufman DS, Lee H, et al. Randomized controlled trial of annual zoledronic acid to prevent gonadotropin-releasing hormone agonist-induced bone loss in men with prostate cancer. J Clin Oncol. 2007;25:1038-1042.

89. Ryan CW, Huo D, Bylow K, et al. Suppression of bone density loss and bone turnover in patients with hormone-sensitive prostate cancer and receiving zoledronic acid. BJU Int. 2007;100:70-75.

90. Doran PM, Riggs BL, Atkinson EJ, Khosla S. Effects of raloxifene, a selective estrogen receptor modulator, on bone turnover markers and serum sex steroid and lipid levels in elderly men. J Bone Miner Res. 2001;16(11):2118-2125.

91. Smith MR, Fallon MA, Lee H, and Finkelstein JS. Raloxifene to prevent gonadotropin-releasing hormone agonist-induced bone loss in men with prostate cancer: a randomized controlled trial. J Clin Endocrinol Metab. 2004;89:3841-3846
92. Black DM, Delmas PD, Eastell R, et al; for the HORIZON Pivotal Fracture Trial. Fracture trial once-yearly zoledronic acid for treatment of postmenopausal osteoporosis. N Engl J Med. 2007;356:1809-1822.

93. FDA Medwatch. Bisphosphonates (marketed as Actonel, Actonel+Ca, Aredia, Boniva, Didronel, Fosamax, Fosamax + D, Reclast, Skelid, and Zometa). Washington DC: US Food and Drug Administration. Updated 2008 Jan 7. Cited 2008 Dec 12. Available from: http://www. fda.gov/medwatch/safety/2008/safety08.htm\#Bisphosphonates.

94. Khosla S, Burr D, Cauley J, et al. Bisphosphonate-associated osteonecrosis of the jaw: report of a task force of the american society for bone and mineral research. J Bone Miner Res. 2007;22:1479-1491.

95. Boonyapakorn T, Schirmer I, Reichart PA, Sturm I, Massenkeil G. Bisphosphonate-induced osteonecrosis of the jaws: prospective study of 80 patients with multiple myeloma and other malignancies. Oral Oncol. 2008;44(9):857-869.

96. Heckbert SR, Li G, Cummings SR, Smith NL, Psaty BM. Use of alendronate and risk of incident atrial fibrillation in women. Arch Intern Med. 2008;168(8):826-831.

97. Sørensen HT, Christensen S, Mehnert F, et al. Use of bisphosphonates among women and risk of atrial fibrillation and flutter: population based case-control study. BMJ. 2008;336:813-816.

98. US Food and Drug Administration. Update of Safety Review Follow-up to the October 1, 2007 Early Communication about the Ongoing Safety Review of Bisphosphonates Washington DC: US Food and Drug Administration. Updated 2008 Nov 12. Cited 2009 Apr 22. Available from: http://www.fda.gov/CDER/drug/early_comm/ bisphosphonates_update_200811.htm.
Clinical Interventions in Aging

\section{Publish your work in this journal}

Clinical Interventions in Aging is an international, peer-reviewed journal focusing on evidence-based reports on the value or lack thereof of treatments intended to prevent or delay the onset of maladaptive correlates of aging in human beings. This journal is indexed on PubMed Central, MedLine, the American Chemical Society's 'Chemical

\section{Dovepress}

Abstracts Service' (CAS), Scopus and the Elsevier Bibliographic databases. The manuscript management system is completely online and includes a very quick and fair peer-review system, which is all easy to use. Visit http://www.dovepress.com/testimonials.php to read real quotes from published authors. 